\title{
From collaborative business practices to user's adapted visualization services: towards a usage-centered method dedicated to the AEC sector
}

\author{
Gilles Halin $^{1}$, Sylvain Kubicki ${ }^{2}$, Conrad Boton ${ }^{1,2}$, Daniel Zignale ${ }^{1,2}$ \\ ${ }^{1}$ FRE MAP-CRAI, Research Centre in Architecture and Engineering. 2 rue Bastien-Lepage \\ B.P. 40435 - 54001 Nancy Cedex, Nancy, France. \\ Gilles.Halin@crai.archi.fr \\ ${ }^{2}$ Henri Tudor Public Research Centre. 29, avenue John F. Kennedy, Luxembourg-Kirchberg, \\ Luxembourg. \\ \{Sylvain.Kubicki, Conrad.Boton, Daniel.Zignale\}@tudor.lu
}

\begin{abstract}
Visualization of the cooperation context is an important issue, especially when applied to complex and unstable collective activities, as it is the case in the field of Architecture, Engineering and Construction (AEC). With the aim of assisting cooperative construction projects it is important to propose business services and user views adapted to user's business requirements. This paper presents the concept of "adapted visualization service" and a usagecentered method that enables to design visualization services adapted to actor's business needs.
\end{abstract}

Keywords: collaborative practice, visualization services, adapted visualization, usage-centered method, cooperative context, business requirement.

\section{Introduction}

Service-oriented groupware systems supporting the cooperative activities are emerging. They propose IT services that can be used by all the actors during projects of a significant size. Most of these 'large projects' use this type of platform to improve communication between stakeholders. The organization of the actors involved in these projects tends to make uniform the methods of work and the resources management. In most cases, "custom-made" software solutions are implemented and used efficiently in the framework of these contexts of durable cooperation between organizations. However such standardized methods are not common in Architecture, Engineering and Construction (AEC) industry [1].

Indeed, AEC projects involve temporarily teams of heterogeneous actors (architects, engineers, contractors, etc.) able to respond to the customer's requirements. Each of these heterogeneous firms has its own internal processes, methods and IT infrastructures. Then cooperative activities in the AEC sector are different from one project to another. Each project generates its own cooperative 
context, i.e. a set of specific stakeholders, particular processes or communication practices.

Visualization of such cooperation context is an important issue, especially when applied to complex and unstable collective activities, as it is the case in the field of AEC. In order to consolidate the cooperation context, it is important to propose business services and user views adapted to user's business requirements. Therefore, the concept of "business visualization service" is developed in order to take into account such requirements in service systems developments. Our main hypothesis is that visualization in services systems user interfaces have to fit actors' usages. Indeed, actors have specific practices according to their roles in an activity.

This approach suggests a usage-centered method to design Adapted Visualization Services (AVS), describing collaborative practices, usages, and visualization services, and the relationships between their concepts. This method, inspired from UI design methods from software engineering [2] or HCI domains [3], integrates an innovative visualization service design process which guides the AVS configuration according to the identification of a set of collaborative practices needed in a collaborative project.

\section{Towards a method to design adapted visualization services}

To design adapted visualization services for each actor business needs in a collaborative tool, a method based on a 4-steps process is proposed (Fig. 1). Each step of the method is supported by appropriate meta-models. Indeed, Model Driven Engineering approach recommends the use of meta-models to define domain languages, thus each model has to be conformed to its meta-model $[4,5]$.

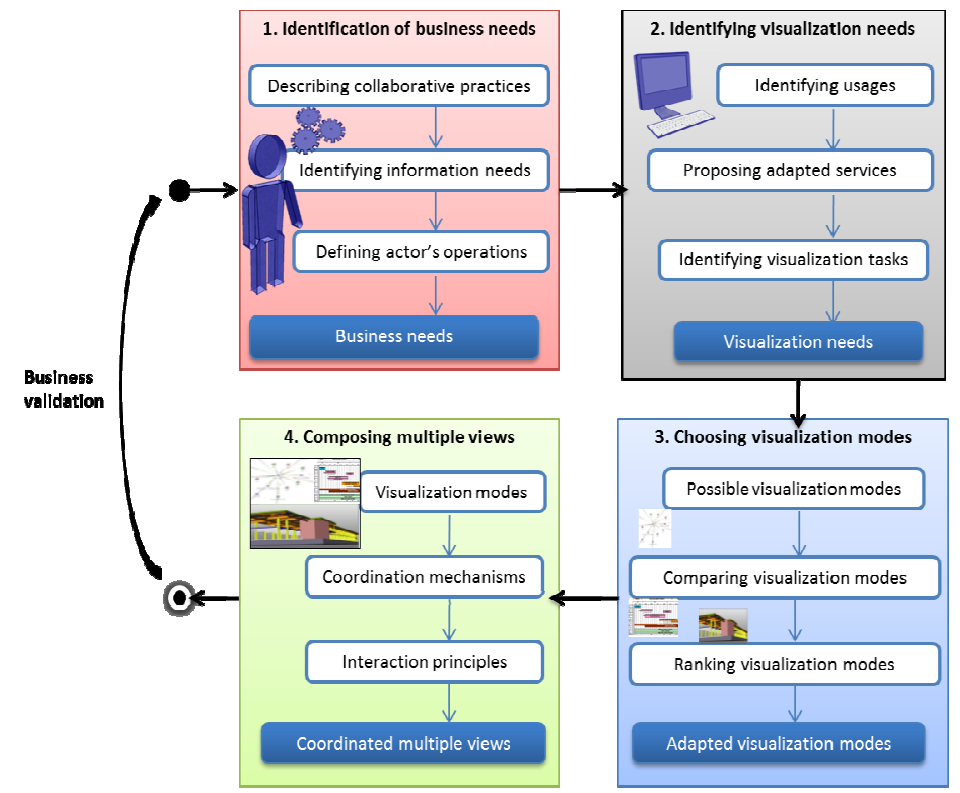

Fig. 1. Method to compose adapted visualization techniques 


\subsection{Identifying actor's business needs (Step 1)}

The first step identifies the business needs of actors. This consists in formalizing the collaborative practices and decomposing them in more role-specific practices. Knowing these practices helps to better define the business needs. Collaborative Practices (CPs) are defined as the behaviors of groups of actors (at least two) working together in various organizational situations according to business objectives [6]. These objectives are related to the AEC project requirements. Then, such CPs can be repeatable until the objectives achievement. CPs are decomposed focusing on each actor and defining their own practices: the Individual Practices (IPs). Each IP is defined by a business individual goal and composed of several Operations. Finally, usages - defined by an instrumental nature - confront actors to specific tools which support their operations. Each usage has its own context depending on the device used, its usual localization, or its frequency... (Fig 2).

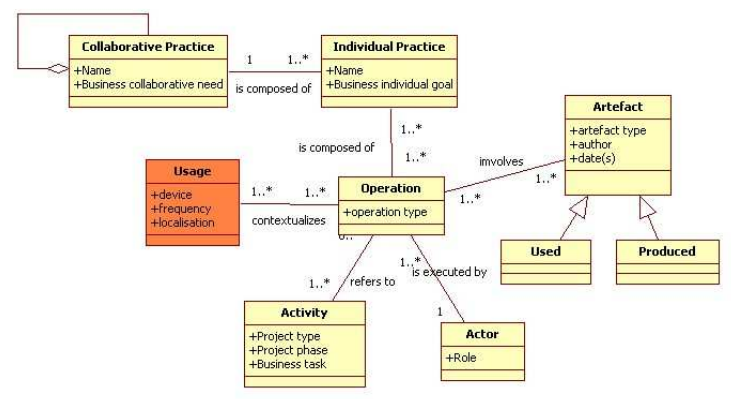

Fig. 2.Usage Meta-Model (UMM)

The Usage Meta-Model (UMM) characterizes this description. The concept of usage defines the context of execution of business operations (device used, localization, frequency...). The aim is the identification of standards operations performed in business activities, like "share", "consult", "create", "modify", "require"...One can see in the UMM which actors are responsible of each operation. The actors are defined by their business role in the project. The UMM also precises which artefacts are used or produced (i.e. documents like plans, meeting reports but also objects like materials or not formalized artefacts like reactions or validations). These artefacts can be characterized by their author(s) and some related dates (date of creation, modification, sharing...). Finally, operations are related to project types, phases and tasks. All these elements describe the business specificities that have to be considered.

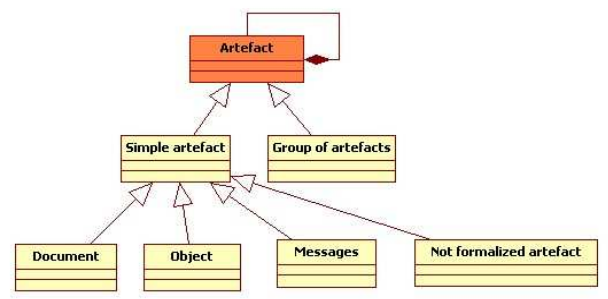

Fig. 3.The artifact concept characterized in the cooperative context meta-model 
The particularity of this approach is that the business-related concepts (actors, artifacts, activities) are already identified in a domain model, i.e. the Cooperative Context Meta-Model (CCMM) of a construction project [5]. There is no need to redefine them. A part of this CCMM illustrated in fig. 3 represents how businessrelated concepts (here the concept of artefact) are described.

Based on the meta-models defined, each collaborative situation can be described accurately. The second step of the method consists of defining visualization tasks for each role-specific operations and corresponding usages identified in a CP.

\subsection{Identifying visualization needs (step 2)}

When the collaborative practices are identified and decomposed into standard operations with their related usages, the corresponding visualization needs can be identified. Indeed, this is very important in order to adapt visualization services that will be provided to support actor's needs. In our specific context, visualization needs are the visualization tasks and interactions that a user will need to perform in front of a computer-supported tool. Visualization tasks are the "analytic and exploratory tasks that he might need or want to perform on the data" [6]. A visualization tasks metamodel is proposed (Fig 4), relying on [9].

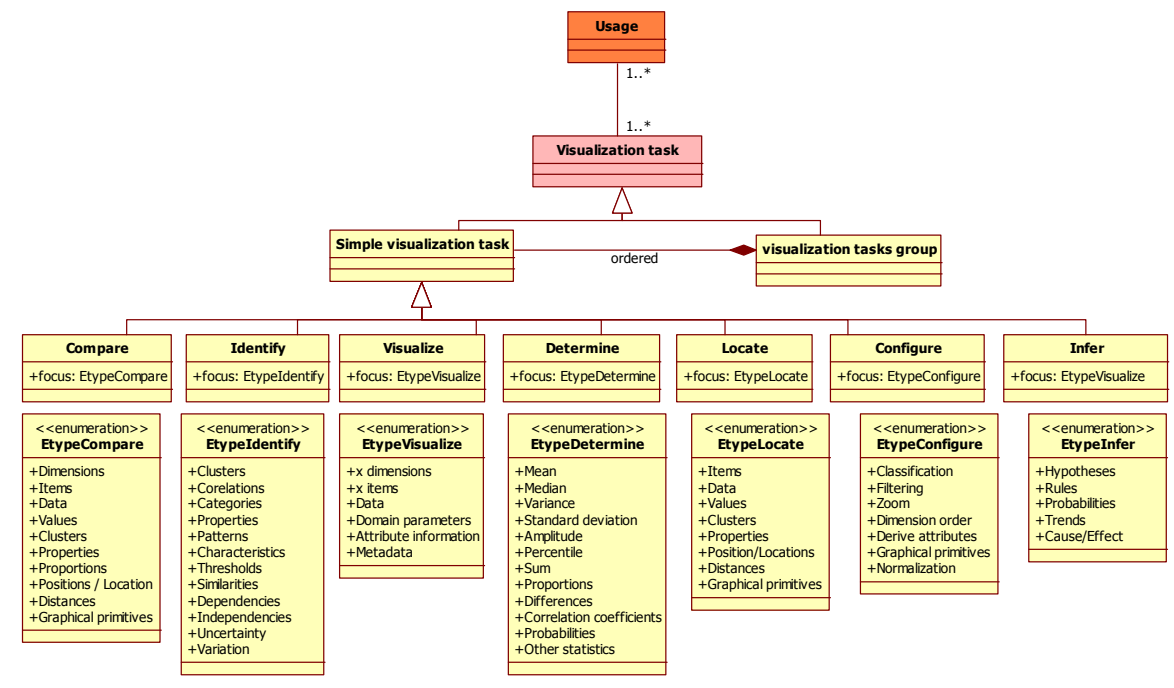

Fig. 4. User's visualization tasks meta-model.

\subsection{Choosing adapted visualization modes (step 3)}

As one knows, many visualization techniques can exist to represent the same information. For example, both Gantt chart and PERT network can depict an activity planning. Whenever possible, we will appeal to business view. "Business views" are the visualization modes that practitioners use in their daily work. The purpose of this 
step is to choose the most adapted views for given usages. Firstly, it is useful to describe possible visualization modes in order to compare them. To this end, a business view meta-model is proposed (Fig. 5). That will help in describing possible business views according to the same formalism.

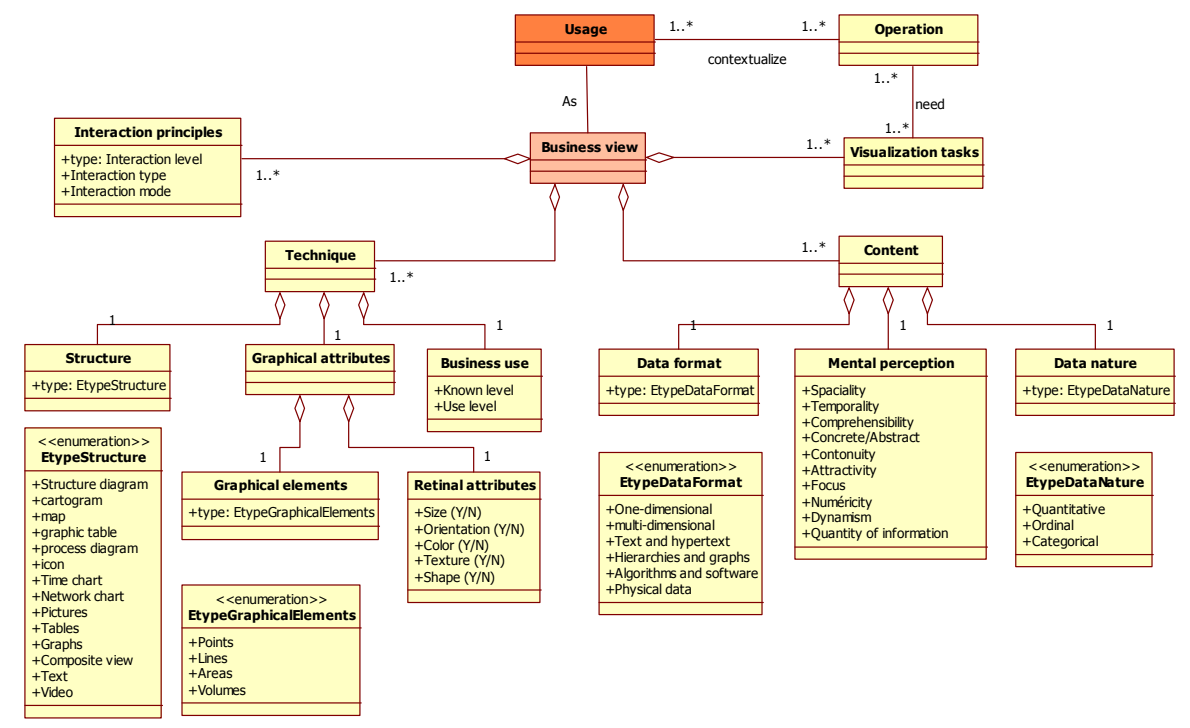

Fig. 5. Business view meta-model

But even if this description is necessary, it is not sufficient to choose the most adapted among the possible visualization modes. It is then useful to be able to rank them. A ranking system is proposed and enables to attribute a score for each business view.

This adaptation score $(A s)$ is calculated for each actor and each Usage with the formula below. The business view properties (fig.5) are used as criteria. The MetaModel characterized these criteria and the matching between Business view and Usage through the As.

$$
A s=\frac{\sum_{i=1}^{n} N c_{i}}{n} \quad \text { with } \quad N c_{i}=\frac{\sum_{j=1}^{m} P_{j}}{m}
$$

As is the average of the $N c i$ and $\mathrm{n}$ is the number of criteria while $\mathrm{m}$ is the number of proprieties for a criterion $i$. The score $\left(N c_{i}\right)$ of a criterion $\mathrm{i}$ is then the average of its properties relevance $\left(P_{j}\right)$ scores according to a visualization requirement. The visualization requirement is both an information need and a need for visualization tasks. The properties relevance scores $\left(P_{j}\right)$ are $-1,0$ or 1 depending on whether the property $j$ is clearly unsuited, poorly adapted or well suited to the sub-practice. Each $N c_{i}$ value may vary between -1 and 1 . 


\subsection{Composing adapted visualization services (step 4)}

When the most adapted visualization modes are chosen for each business need of an actor, it is then possible to put them together in order to propose coordinated multiple views. An Adapted Visualization Service (AVS) is a set of adapted services proposed with appropriate coordinated multiple views to display information. So, for each business role, the appropriate coordination mechanisms and interaction principles will be determined. Exploration techniques and coordination control are two of the fundamental areas of coordinated and multiple views [8]. The utility of multiple coordinated views comes from users' ability to express multidimensional queries through simple forms of interaction [11]. To compose coordinated views, the $2 \times 3$ taxonomy of multiple window coordination from [11] and the state of the art proposed by [8] are some interesting starting points. So, relied on these literature references and our specific needs, work is ongoing in order to propose an adapted visualization service meta-model.

\section{Case study}

Eleven Collaborative Practices [12] were distinguished during the principal phases of a construction project realization (preparation, design and execution phases). This distinction has emerged through an analysis of project descriptions and brainstorming with professionals. Depending on the context, each Collaborative Practice can be specified and divided in sub-practices. In this case study the $\mathrm{CP}$ related to the "execution preparation and management" is considered. This CP gathers site scheduling, material management, feedback formulation from contractors, etc. Attention will particularly be focused on the "site scheduling" collaborative subpractice.

Table 1 considers both step 1 and 2 of our method. It represents the "site scheduling" collaborative sub-practice, decomposed in Individual Practices and Operations with their related Usages. Then, it defines corresponding visualization tasks.

When visualization tasks are known, possible visualization techniques comparison is needed in order to choose the most adapted one according to these needs. In instance, for the individual practice "Activities sequencing", actor need to visualize the dates, the activities durations and a building representation. The building representation could be a $2 \mathrm{D}$ plan or a $3 \mathrm{D}$ representation (Fig. 6). 
Table 1.Site scheduling collaborative practice and related usages and visualization tasks

\begin{tabular}{|c|c|c|c|c|}
\hline $\begin{array}{l}\text { Collaborative } \\
\text { practice }\end{array}$ & $\begin{array}{l}\text { Individual } \\
\text { practices }\end{array}$ & Operations & Usages & Visualization tasks \\
\hline \multirow{20}{*}{$\begin{array}{l}\text { Collaborative site } \\
\text { scheduling }\end{array}$} & \multirow{3}{*}{$\begin{array}{l}\text { Building } \\
\text { elements } \\
\text { listing }\end{array}$} & Consult elements pre-list & \multirow{3}{*}{$\begin{array}{l}\text { - Architect consults documents } \\
\text { from his office } \\
\text { - Architect edits listings from } \\
\text { his office } \\
\text { - Architect shares listings } \\
\text { information from his office }\end{array}$} & Visualize (focus: data) \\
\hline & & Look for appropriate elements & & Locate (focus: items) \\
\hline & & Create elements listing & & Configure (focus: classification) \\
\hline & \multirow{4}{*}{$\begin{array}{l}\text { Activities } \\
\text { definition }\end{array}$} & Consult activities pre-list & \multirow{4}{*}{$\begin{array}{l}\text { - Supervisor consults } \\
\text { documents and items from } \\
\text { his office } \\
\text { - Supervisor edits listings from } \\
\text { his office } \\
\text { - Supervisor shares listings } \\
\text { information from his office }\end{array}$} & Visualize (focus: data) \\
\hline & & Consult building elements & & Locate (focus: items) \\
\hline & & Look for appropriate activities & & Identify (focus: correlations) \\
\hline & & Create activities listing & & Configure (focus: classification) \\
\hline & \multirow{3}{*}{$\begin{array}{l}\text { Activities } \\
\text { duration } \\
\text { estimation }\end{array}$} & Consult activities & \multirow{3}{*}{$\begin{array}{l}\text { - Sub-contractor consults items } \\
\text { from his office } \\
\text { - Sub-contractor draws } \\
\text { conclusions from his office } \\
\text { - Sub-contractor shares } \\
\text { activities duration from his } \\
\text { office }\end{array}$} & Visualize (focus: data) \\
\hline & & Understand activities consistency & & $\begin{array}{l}\text { Configure (focus: filtering) } \\
\text { Determine (focus: means) }\end{array}$ \\
\hline & & Estimate activities duration & & Infer (focus: hypotheses) \\
\hline & \multirow{5}{*}{$\begin{array}{l}\text { Activities } \\
\text { sequencing }\end{array}$} & Consult activities and durations & \multirow{5}{*}{$\begin{array}{l}\text { - Contractor consults } \\
\text { documents from his office } \\
\text { - Contractor looks for } \\
\text { information from his office } \\
\text { - Contractor edits planning } \\
\text { information from his office } \\
\text { - Contractor shares conflicts } \\
\text { and dates information from } \\
\text { his office }\end{array}$} & Visualize (focus: data) \\
\hline & & $\begin{array}{l}\text { Study relationships and } \\
\text { dependencies among activities }\end{array}$ & & $\begin{array}{l}\text { Identify (focus: correlations) } \\
\text { Identify (focus: dependencies) }\end{array}$ \\
\hline & & Verify conflicts & & Infer (focus: trends) \\
\hline & & Associate start/end dates & & Configure (focus: classification) \\
\hline & & Define site planning & & Configure (focus: normalization) \\
\hline & \multirow{5}{*}{$\begin{array}{l}\text { Schedule } \\
\text { development }\end{array}$} & Consult activities listing & \multirow{5}{*}{$\begin{array}{l}\text { - Supervisor consults } \\
\text { documents and items from } \\
\text { his office } \\
\text { - Supervisor edits planning } \\
\text { information from his office } \\
\text { - Supervisor shares project } \\
\text { plan information from his } \\
\text { office }\end{array}$} & Visualize (focus: data) \\
\hline & & Consult actors listing & & Visualize (focus: data) \\
\hline & & Associate actors and activities & & Identify (focus: correlations) \\
\hline & & Include planning & & Infer (focus: trends) \\
\hline & & Realize project plan & & Configure (focus: classification) \\
\hline
\end{tabular}

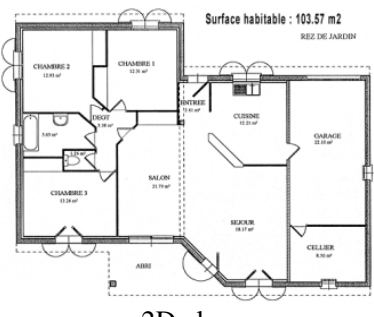

2D plan

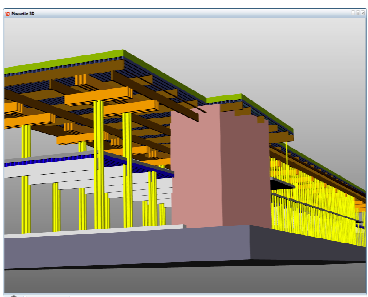

$3 \mathrm{D}$ representation

Fig. 6. Proposal for building representation modes

After describing them, their adaptation score (As) can be calculated following the step 3. Results for the present case study are represented in table 2 . The score in this table are not validated yet and future works will focus on it and, more generally, on practitioner's evaluation of business views according to their experience. However, the example in table 2 can show that the 3D representation is more adapted than the 2D plan. 
Table 2.Calculation of visualization modes adaptation score

\begin{tabular}{|c|c|c|c|}
\hline Criteria & Proprieties & $\begin{array}{l}\text { 3D } \\
\text { rep. }\end{array}$ & $\begin{array}{c}2 \mathrm{D} \\
\text { plan }\end{array}$ \\
\hline \multirow[t]{5}{*}{ Technique } & Structure & 0 & -1 \\
\hline & Graphical elements & 1 & 0 \\
\hline & Retinal attributes & 1 & 0 \\
\hline & Business use & 0 & 1 \\
\hline & $\mathrm{Nc}_{1}$ & 0,5 & $\mathbf{0}$ \\
\hline \multirow[t]{4}{*}{ Content } & Data Format & 1 & 1 \\
\hline & Mental perception & 0 & -1 \\
\hline & Data nature & 0 & -1 \\
\hline & $\mathrm{Nc}_{2}$ & 0,33 & $-0,33$ \\
\hline \multirow{3}{*}{$\begin{array}{l}\text { Interaction } \\
\text { principles }\end{array}$} & Interaction level & 1 & -1 \\
\hline & Interaction type & 0 & -1 \\
\hline & $\mathrm{Nc}_{3}$ & 0,5 & -1 \\
\hline \multirow{3}{*}{$\begin{array}{l}\text { Visualization } \\
\text { tasks }\end{array}$} & Visualisation tasks & 1 & 0 \\
\hline & $\mathrm{Nc}_{4}$ & 1 & $\mathbf{0}$ \\
\hline & As & $\mathbf{0 , 5 8}$ & $-\mathbf{0 , 3 3}$ \\
\hline
\end{tabular}

Same work for each other usages will lead to know all the needed adapted visualization modes for each actor. In the last step, interactions and coordination mechanism will be associated in order to build adapted visualization services for all the actors.

\section{Conclusion}

The paper presents a usage-centered method that enables to design "Adapted Visualization Services". It considers actor's business Usages related to the "Collaborative Practices" (CP) in which they are involved. The models that support each step are presented and a formula is proposed to rank visualization modes. This method is illustrated through a case study related to the site scheduling business Collaborative Practice.

In the future, focus will be on the fourth step of the method which is still in an early stage of development. It will be particularly formalized by proposing a coordinated multiple views meta-model. The advantage of this model-driven approach is the possibility to support it by software tools. The design of such tools that will support the method will allow us to 1) extend it to other case studies and 2) confront it to professionals in order to validate both the method and the final propositions in terms of Visualization Modes. The possibility to represent graphically the CPs through diagrams is explored using the Eclipse environment and particularly the GMF framework (Graphical Modeling Framework). 


\section{Acknowledgment:}

This article is supported by the National Research Fund, Luxembourg.

\section{References}

[1] P. Nitithamyong, "Web-based construction project management systems: how to make them successful?," Automation in Construction, vol. 13, Jul. 2004, pp. 491-506.

[2] L.L. Constantine and L. a D. Lockwood, "Usage-centered engineering for Web applications," IEEE Software, vol. 19, 2002, p. 42-50.

[3] J. Coutaz and G. Calvary, "HCI and Software Engineering: Designing for User Interface Plasticity," The Human Computer Interaction Handbook, A. Sears and J.A. Jacko, eds., Lawrence Erlbaum Associates, 2008, pp. 1107-1125.

[4] J.M. Favre, "Towards a basic theory to model model driven engineering," 3rd Workshop in Software Model Engineering, WiSME, Citeseer, 2004.

[5] J.S. Sottet, G. Calvary, J.M. Favre, J. Coutaz, and A. Demeure, "Towards mapping and model transformation for consistency of Plastic User Interfaces," Computer Human Interaction, Workshop on The Many Faces of Consistency in Cross-platform Design, Citeseer, 2006, pp. 9-12.

[6] K. Schmidt, "Cooperative Work and Coordinative Practices," Computer Supported Cooperative Work, London: Springer London, 2011, pp. 3-27.

[7] S. Kubicki, J.C. Bignon, G. Halin, and P. Humbert, "Assistance to building construction coordination - towards a multi-view cooperative platform," ITcon Vol. 11, 2006, pp. 565-586.

[8] E.R.A. Valiati, M.S. Pimenta, and C.M.D.S. Freitas, "A taxonomy of tasks for guiding the evaluation of multidimensional visualizations," BELIV '06: Proceedings of the 2006 AVI workshop on BEyond time and errors, New York, NY, USA: ACM, 2006, pp. 1-6.

[9] C. Boton, S. Kubicki, and G. Halin, "Method to design coordinated multiple views adapted to user's business requirements in 4D collaborative tools in AEC," Proceedings of 15th IEEE International Conference on Information Visualization, London (United Kingdom): 2011.

[10] J.C. Roberts, "State of the Art: Coordinated \& Multiple Views in Exploratory Visualization," Fifth International Conference on Coordinated and Multiple Views in Exploratory Visualization (CMV 2007), Jul. 2007, pp. 61-71.

[11] M.Q. Wang Baldonado, A. Woodruff, and A. Kuchinsky, "Guidelines for using multiple views in information visualization," AVI '00: Proceedings of the working conference on Advanced visual interfaces, New York, NY, USA: ACM, 2000, pp. $110-119$.

[12] C. North and B. Shneiderman, A Taxonomy of Multiple Window Coordinations, University of Maryland, College Park, Dept of Computer Science: 1997.

[13] D. Zignale, S. Kubicki, S. Ramel, and G. Halin, "A model-based method for the design of services in collaborative business environments," Proceedings of IESS 1.1: Second International Conference on Exploring Services Sciences, Geneva, Switzerland: 2011, p. 15. 